\title{
ULTRASONOGRAPHY EVALUATION FOR PREDOMINANT CONTENT OF APPENDIX
}

\author{
Krishna Kumar R1, Adarsh A. D2, Venugopal Kodumur 3 , Manas Kumar Bora ${ }^{4}$
}

${ }^{1}$ Associate Professor, Department of Radiology, Aarupadai Veedu Medical College and Hospital, Pondicherry. ${ }^{2}$ Assistant Professor, Department of Radiology, Aarupadai Veedu Medical College and Hospital, Pondicherry. ${ }^{3}$ Senior Resident, Department of Radiology, Aarupadai Veedu Medical College and Hospital, Pondicherry. ${ }^{4}$ Professor, Department of Radiology, Aarupadai Veedu Medical College and Hospital, Pondicherry.

\section{ABSTRACT}

\section{BACKGROUND}

Appendicitis is a common cause for acute abdomen. Many literatures are available on imaging appendicitis and visualisation of normal appendix, but very limited studies for predominant contents of appendix by ultrasonography.

Aim- To analyse contents of appendix in normal and inflamed appendix and to find if any content has association with inflammation of appendix and severity of inflammation.

\section{MATERIALS AND METHODS}

A prospective study was conducted in the period, January 2014 to January 2016 . Two hundred patients were selected for this study, who presented with clinical symptoms and signs pertaining to acute appendicitis. The role of ultrasonography in detecting predominant content of appendix in normal and inflamed appendix and the results were analysed to associate if any specific content correlates with the inflammation of appendix and severity of inflammation. Contents analysed were lith (echogenic foci with posterior acoustic shadow), faecal matter (echogenic foci without posterior acoustic shadow), pus or fluid with faecal matter (fluid with internal echoes) and Mucocoele (fluid without internal echoes).

\section{RESULTS}

Echogenic foci without posterior acoustic shadow (faecal matter) was the more common content in normal appendix having diameter of 4.1-6 mm (27\%) (lith). Echogenic foci with posterior acoustic shadow (lith) are more common in inflamed appendix (7 $\%)$. Complication was also more common in inflamed appendix having lith as content. Echogenic foci with ring-down artefact or indistinct posterior shadow (air) was more common in normal appendix (4\%). Diameter of appendix is commonly less than $5.1 \mathrm{~mm}$ when air is the content of appendix.

\section{CONCLUSION}

Ultrasonography is an excellent mode of investigation to diagnose acute appendicitis. The usefulness of high frequency probe and graded compression method has a high diagnostic value for acute appendicitis. Evaluation of contents of appendix may be useful when diameter is intermediate around $6 \mathrm{~mm}$. More weightage can be given to consideration that appendix is normal when the content is Faecal matter. When Fluid with internal echoes is present, it favours more towards acute appendicitis as diagnosis. Severity of inflammation is more when appendicolith is present, this may be due to obstruction caused by lith. In conclusion, evaluation of content of appendix is important in diagnosing acute appendicitis especially when diameter is intermediate. This is a first effort on evaluation of contents, further studies are needed.

\section{KEYWORDS}

Contents of Appendix, Ultrasonography, Predominant Contents.

HOW TO CITE THIS ARTICLE: Kumar KR, Adarsh AD, Kodumur V, et al. Ultrasonography evaluation for predominant content of appendix. J. Evolution Med. Dent. Sci. 2017;6(34):2828-2832, DOI: 10.14260/Jemds/2017/608

\section{BACKGROUND}

\section{Aims}

To analyse contents of appendix in normal and inflamed appendix and to note if any content has association with inflammation of appendix and severity of inflammation.

\section{MATERIALS AND METHODS Study Plan}

A prospective study of the role of ultrasonography in detecting contents of appendix along with wall thickness

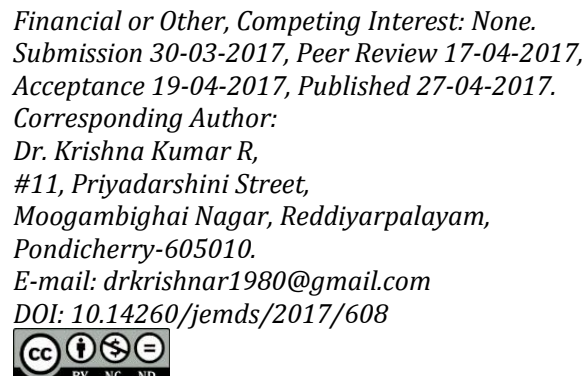
and results were analysed to associate if any specific content correlates with inflammation of appendix and severity of inflammation.

Study was conducted in the period, January 2014 to January 2016. 200 patients were selected for this study, who presented with clinical symptoms and signs pertaining to acute appendicitis.

All procedures performed in studies involving human participants were in accordance with the ethical standards of the institutional and/or national research committee and with the 1964 Helsinki declaration and its later amendments or comparable ethical standards.

Informed consent was obtained from all individual participants included in the study.

Scanning, Methods and Transducers used-

- Initial scanning.

- Scanning with graded compression technique. 
- Followup scanning after fasting/bowel preparation if needed.

\section{Transducers used in the Present Study-}

- Linear Array, $6 \mathrm{MHz}$ to $11 \mathrm{MHz}$.

- Curvilinear Array, 3.0 to $6 \mathrm{MHz}$.

- Tissue harmonic imaging T4.6 to T5.

\section{Criteria}

Any patient whose clinical presentation suggested acute appendicitis or patient having right lower quadrant pain or lower abdominal pain in which acute appendicitis is included in differential diagnosis and in whom ultrasound examination was done as a primary investigation.

All patients who could be rescanned after bowel preparation to research, diagnose or follow for surgical/histopathological confirmation.

Patients are excluded who presented with symptoms related to other organ system and when ultrasound was not used as an initial evaluation method.

Any patient having excessive bowel gas, in whom even with bowel preparation and graded compression sonography, if visualisation of appendix becomes difficult, was excluded from study.

Ultrasonography findings are correlated only with peroperative finding and histopathological finding. In patients with normal appendix only sonographic criteria was taken for assessment of contents, as it is reliable than any other investigation in this regard.

\section{Classification of Contents of Appendix}

1. Echogenic substance with posterior acoustic shadow. (Appendicolith)

2. Echogenic substance without posterior acoustic shadow. (Faecal Matter)

3. Echogenic substance with indistinct posterior acoustic shadow. (Air)

4. Anechoic substance without internal echoes. (Clear Fluid Like Mucus)

5. Anechoic substance with internal echoes. (Pus, Mucus, and Faecal Mixed Fluid)

\section{Evaluation of Contents of Appendix}

Contents of normal appendix and abnormal appendix can be evaluated using USG first classifying either solid or fluid which can be done with sonography with great accuracy than computed tomography. Then solids are classified as faecal matter which does not show posterior acoustic shadow (Figure.1A \& B) or lith as lith causes posterior acoustic shadow (Figure 2A \& B). Air is echogenic like appendicolith but air has to be differentiated from lith by its indistinct posterior shadow and ring-down artefact caused by air (Figure 3 ).

Fluids also classified as one having internal echoes (Figure. 4) which may be pus, faeces mixed fluid, haemorrhagic fluid and combination of any of these contents. Fluid without internal echoes (Figure. 5) is due to Mucocoele though the condition is rare. Low level internal echoes may be present in Mucocoele due to its high protein content.

\section{Statistical Analysis}

The age of the patients involved in study ranges from first decade to sixth decade. Acute appendicitis is more common in 20-40 yrs. of age group. Forty-eight (48) patients had appendicitis in 20 to 30 years age group and 36 patients had appendicitis in 30 to 40 years of age group No evidence of sex preponderance seen. Out of 200 patients 105 were females and 95 were males.

Incidence of Echogenic foci without posterior acoustic shadow (faecal matter) is more common content in normal appendix $27 \%$ compared to inflamed appendix $7 \%$ (table-1). Incidence of Echogenic foci with posterior acoustic shadow (lith) is more common content in inflamed appendix (Incidence $11 \%$ ) compared to $2 \%$ in normal appendix (table1). Incidence of Echogenic foci with ring-down artefact or indistinct posterior shadow (air) is the more common content in normal appendix, incidence was $4 \%$ compared to $2 \%$ in inflamed appendix (table-1). Anechoic without internal echoes (fluid) is common in inflamed appendix at $8 \%$ as compared to $4 \%$ in normal appendix. Anechoic with internal echoes (pus or fluid with faecal matter) is common in inflamed appendix, Incidence was $27 \%$ compared to $8 \%$ in normal appendix.

\begin{tabular}{|c|c|c|c|}
\hline Predominant Contents of appendix & Inflamed Appendix & Normal Appendix & total \\
\hline Echogenic foci without posterior acoustic shadow (Faecal matter) & 14 & 54 & 68 \\
\hline Echogenic foci with posterior acoustic shadow (Lith) & 21 & 4 & 25 \\
\hline $\begin{array}{l}\text { Echogenic foci with ring-down artefact } \\
\text { or indistinct posterior shadow (Air) }\end{array}$ & 4 & 8 & 12 \\
\hline Anechoic without internal echoes (Fluid) & 8 & 16 & 24 \\
\hline Anechoic with internal echoes (Pus, fluid with faecal matter) & 56 & 15 & 71 \\
\hline
\end{tabular}

\begin{tabular}{|c|c|c|c|c|c|c|c|c|c|c|c|c|}
\hline & \multicolumn{12}{|c|}{ Calibre of Appendix } \\
\hline & & & & $\mathbf{m m}$ & & $\mathbf{n m}$ & & & & & abov & $\mathbf{m m}$ \\
\hline Contents of Appendix & I & $\mathbf{N}$ & I & $\mathbf{N}$ & I & $\mathbf{N}$ & I & $\mathbf{N}$ & I & $\mathbf{N}$ & I & $\mathbf{N}$ \\
\hline $\begin{array}{l}\text { Echogenic foci without posterior acoustic } \\
\text { shadow (faecal matter) }\end{array}$ & 0 & 9 & 0 & 26 & 2 & 13 & 6 & 8 & 4 & 0 & 2 & 0 \\
\hline $\begin{array}{l}\text { Echogenic foci with posterior acoustic shadow } \\
\text { (lith) }\end{array}$ & 0 & 0 & 0 & 2 & 0 & 2 & 4 & 0 & 3 & 0 & 14 & 0 \\
\hline $\begin{array}{l}\text { Echogenic foci with ring } \\
\text { down artefact or indistinct } \\
\text { posterior shadow(air) }\end{array}$ & 0 & 5 & 0 & 3 & 2 & 0 & 0 & 0 & 1 & 0 & 1 & 0 \\
\hline Anechoic without internal echoes (fluid) & 0 & 5 & 0 & 4 & 0 & 5 & 2 & 0 & 2 & 0 & 4 & 0 \\
\hline $\begin{array}{l}\text { Anechoic with internal echoes (pus, } \\
\text { proteinaceous fluid) }\end{array}$ & 0 & 3 & 0 & 6 & 5 & 6 & 5 & 0 & 20 & 0 & 26 & 0 \\
\hline
\end{tabular}




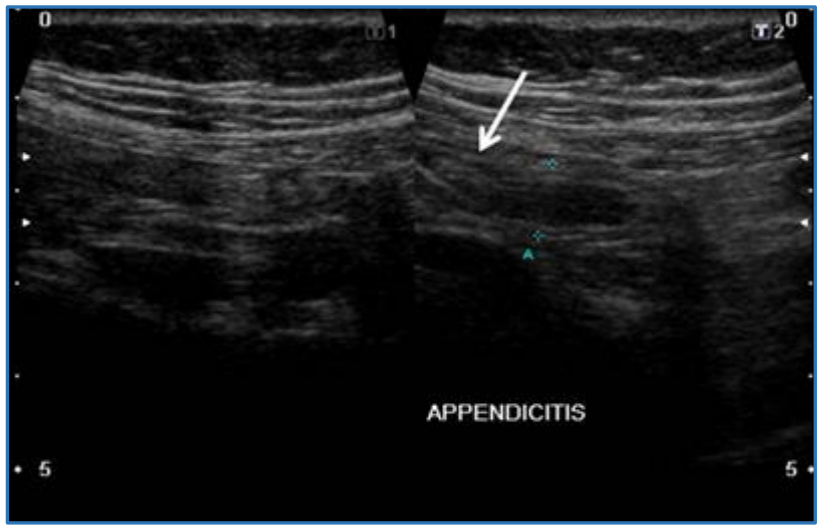

Figure. 1A. Inflamed Appendix having Echogenic Foci without Posterior Acoustic Shadow (Arrow) as Content

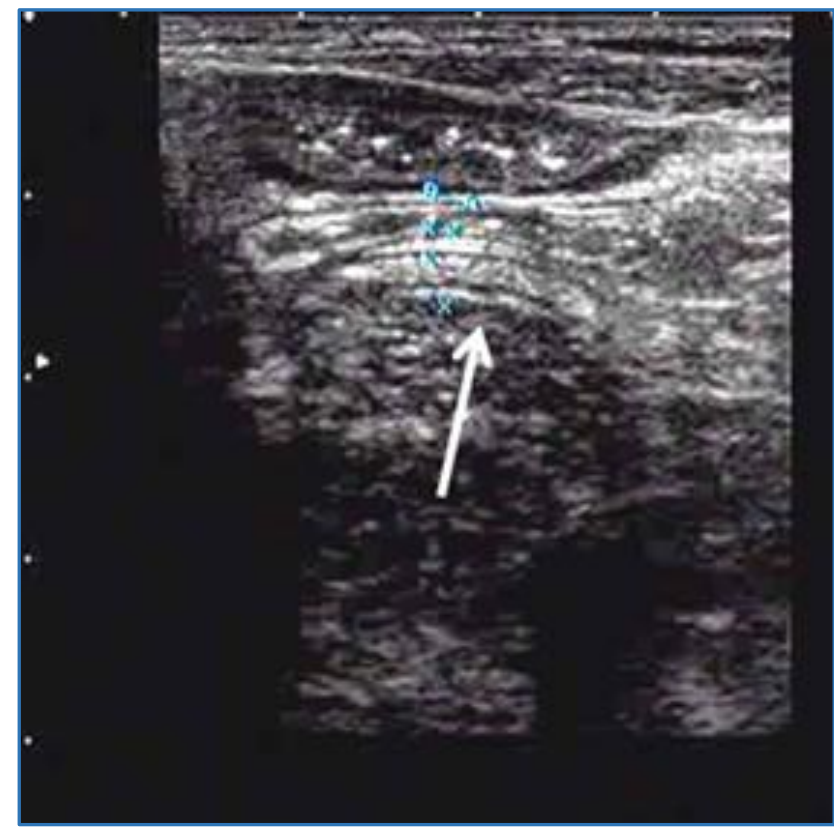

Figure 1B. Normal Appendix having Echogenic Foci without Posterior Acoustic Shadow (Arrow) as Content with Faeces filled Appendix.

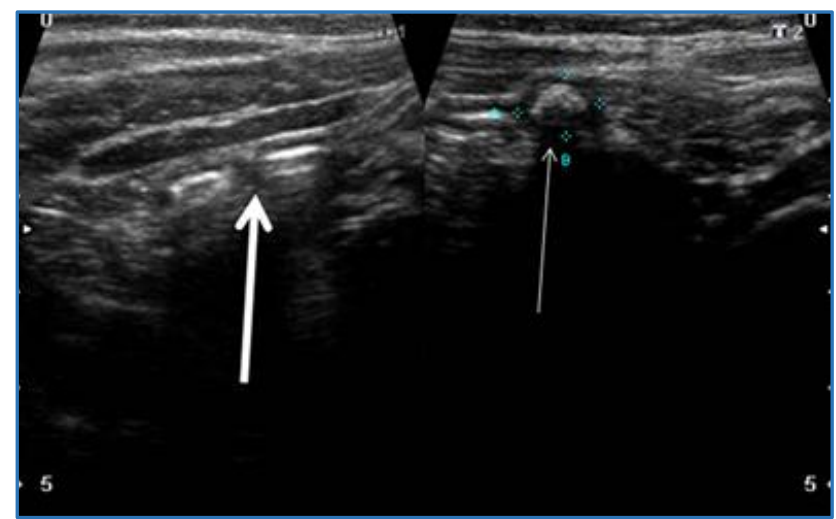

Figure 2A. Normal Appendix (Thick Arrow) showing Faecolith (Thin Arrow) in Distal Part

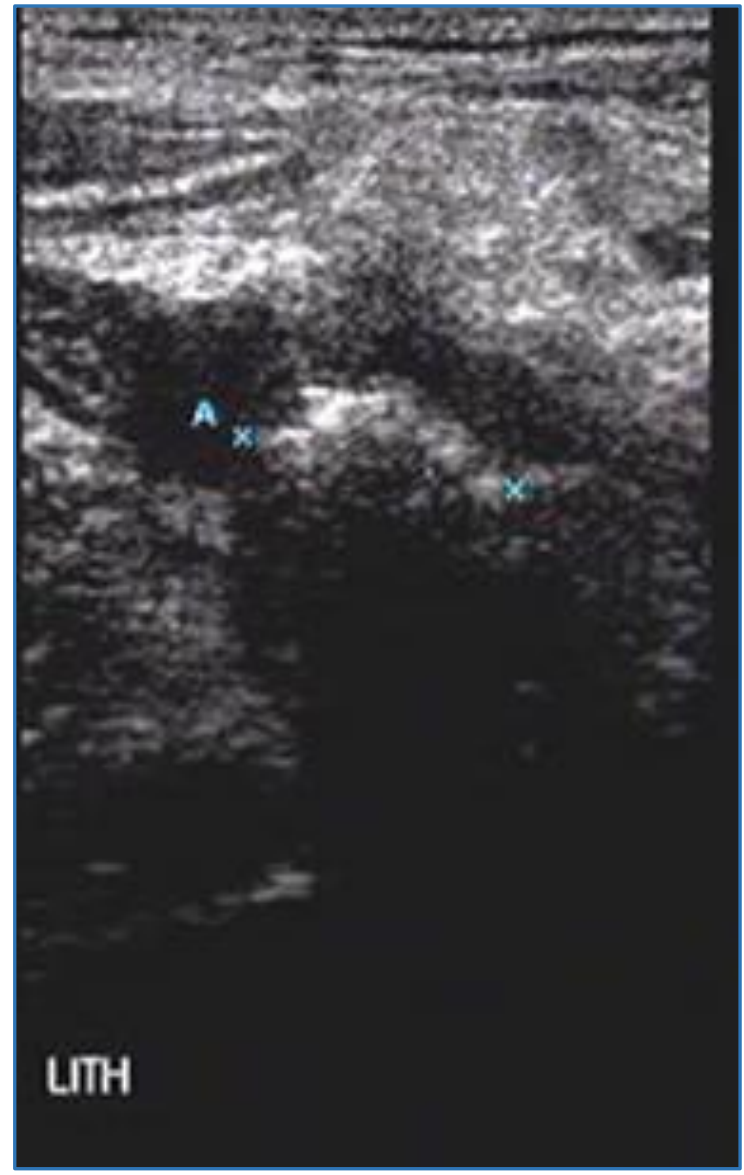

Figure 2B. Inflamed Appendix showing $14 \mathrm{~mm}$ Faecolith (Between Calibres) at Base of Appendix

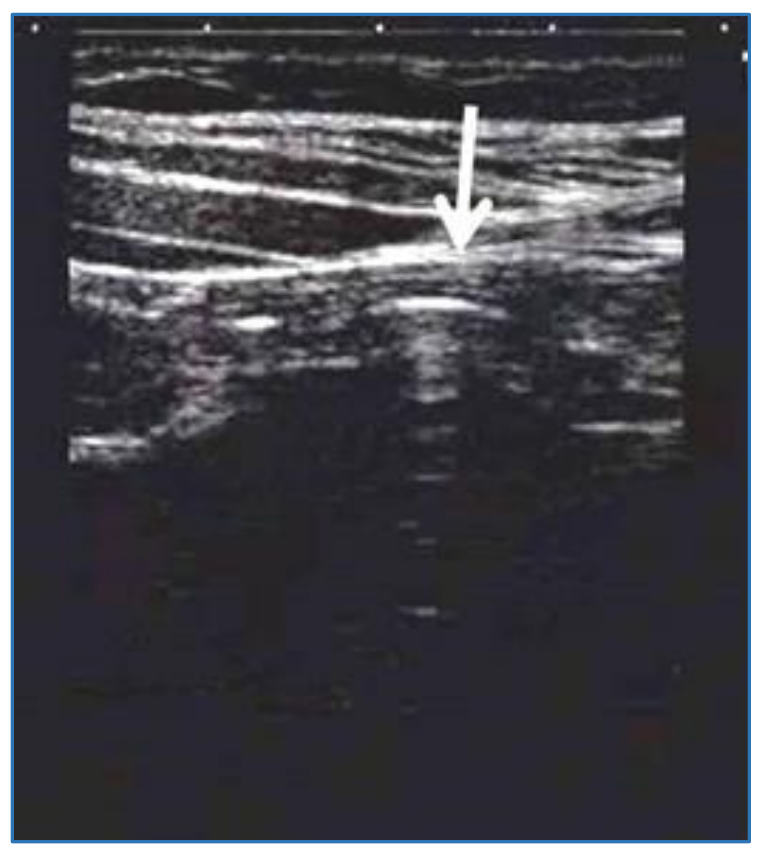

Figure 3. Normal Appendix showing Indistinct Posterior Shadow and Ring-down Artefact Caused by Echogenic Air (Arrow) 


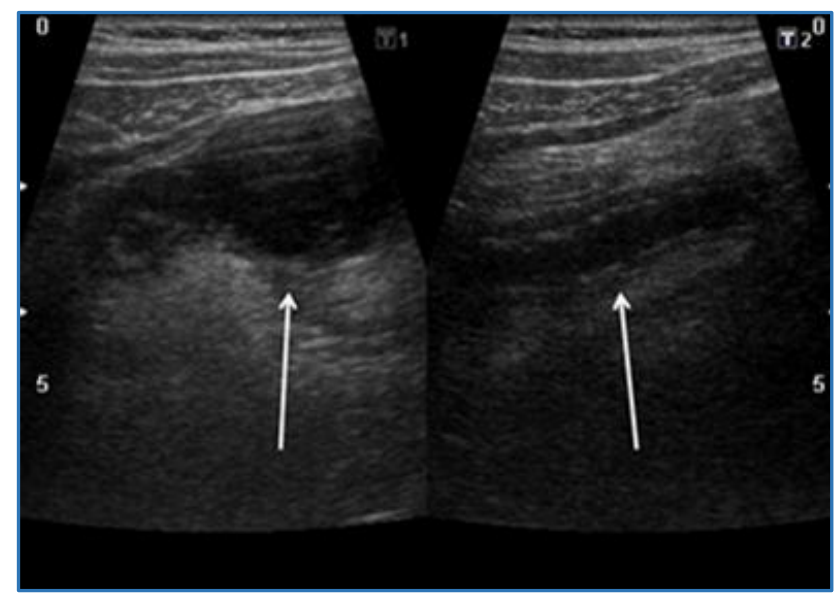

Figure 4. Inflamed Appendix Filled with Fluid having Internal Echoes (Arrow).

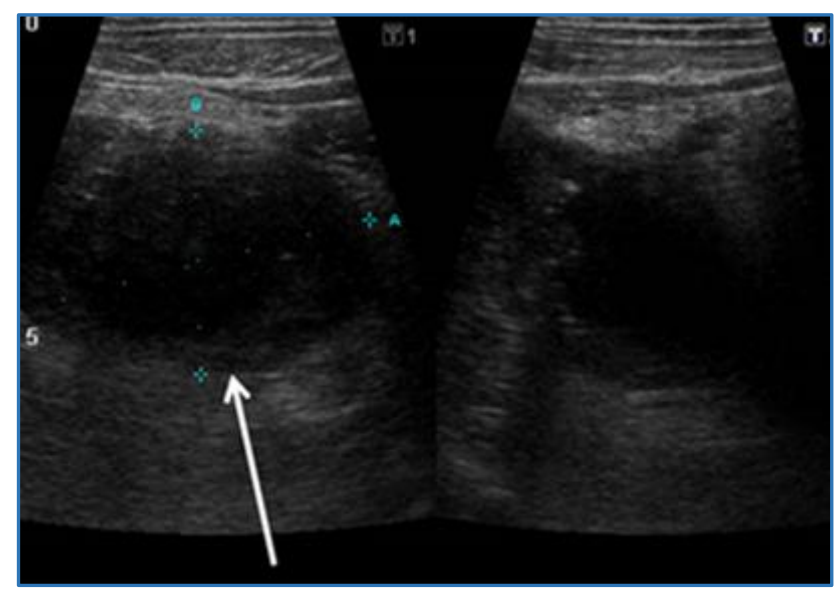

Figure 5. Mucous-filled Distended Appendix which was Proven to be Mucocoele (Arrow) of Appendix

\section{DISCUSSION}

Echogenic foci without posterior acoustic shadow (Faecal matter) are the more common contents in normal appendix (Incidence $27 \%$ for 200 patients). Echogenic foci with posterior acoustic shadow (lith) are the more common contents in inflamed appendix (Incidence of $11 \%$ for 200 patients). Echogenic foci with ring-down artefact or indistinct posterior shadow (air) are the more common contents in normal appendix (Incidence of $4 \%$ for 200 patients). Anechoic without internal echoes (fluid) are common in inflamed appendix (Incidence of 8\% for 200 patients). Anechoic with internal echoes (pus) are common in normal appendix (Incidence of 27\% for 200 patients). Echogenic foci without posterior acoustic shadow (Faecal matter) are the more common contents in normal appendix having diameter of 4.1 $6 \mathrm{~mm}$.

Advantage of this study is that content of appendix can be best evaluated with USG than CT as USG is more sensitive than CT to differentiate fluid from solid content. From this study we can infer that inspissated faecal matter causes an increase in diameter of normal appendix and may cause diagnostic difficulty in diagnosing appendicitis in appendix having diameter in 5.1-6 mm range. Abovementioned finding correlates with study conducted by Simonovský V.(1) Echogenic foci with posterior acoustic shadow (lith) are more common in inflamed appendix. When lith is present severity of inflammation is more (Table 2). Three appendices were having more than $9.1 \mathrm{~mm}$ in diameter. Complication is also more common in inflamed appendix having lith as content. Severely inflamed appendix had perforation in wall of appendix with resultant lump formation. Echogenic foci with ring-down artefact or indistinct posterior shadow (air) are more common in normal appendix and diameter of appendix is consistently less than $5.1 \mathrm{~mm}$ (Table 2). Anechoic without internal echoes (fluid), Anechoic with internal echoes (pus) both are common in inflamed appendix and mucocoele. Anechoic with internal echoes (pus) is more common in severely inflamed appendix. Diameter of appendix may be less than $6.1 \mathrm{~mm}$ in perforated appendix which is encountered in two cases with diameter of 5.8 in one and $6 \mathrm{~mm}$ in another.

Due to developments in instrumentation and resolution, ultrasonography may play a pivotal role in early diagnosis of appendicitis. Delay in surgery for appendicitis results in increased incidence of complications.(2) High-resolution sonography is indicated to establish the diagnosis of acute appendicitis in patients with equivocal clinical findings.(3) The usefulness of high frequency probe and graded compression method has a high diagnostic value for acute appendicitis. $(4,5)$ Superiority of Computed tomography compared to Ultrasonography is overemphasised by many studies $(6,7,8,9,10,11)$ possibly because ultrasonography instrumentation was not very well developed at that time. More studies are needed to compare role of Computed tomography and Ultrasonography at present era. Limitation of this study is relation of contents with wall thickness, wall pattern and perforation of appendix not analysed. Further studies are needed to compare relation of contents with wall thickness, wall pattern and perforation.

\section{CONCLUSION}

Ultrasonography is an excellent mode of investigation to diagnose acute appendicitis. The usefulness of high frequency probe and graded compression method has high diagnostic value for acute appendicitis.(4,5) Evaluation of contents of appendix may be useful when diameter is intermediate around $6 \mathrm{~mm}$. More weightage can be given to consideration that appendix is normal when faecal matter is the content.(1) When fluid with internal echoes is present, it favours more towards acute appendicitis as diagnosis. Severity of inflammation is more when appendicolith is present, this may be due to obstruction caused by lith. In conclusion, evaluation of content of appendix is important in diagnosing acute appendicitis especially when diameter is intermediate.

\section{REFERENCES}

[1] Simonovsky V. Sonographic detection of normal and abnormal appendix. Clin Radiol 1999;54(8):533-9.

[2] Eldar S, Nash E, Sabo E, et al. Delay of surgery in acute appendicitis. Am J Surg 1997;173(3):194-8.

[3] Abu-Yousef MM, Bleicher JJ, Maher JW, et al. Highresolution sonography of acute appendicitis. AJR Am J Roentgenol 1987;149(1):53-8.

[4] Puylaert JB, Rutgers PH, Lalisang RI, et al. A prospective study of ultrasonography in the diagnosis of appendicitis. N Engl J Med 1987;317(11):666-9.

[5] Puylaert JB. Acute appendicitis: US evaluation using graded compression. Radiology 1986;158(2):355-60. 
[6] Raman SS, Lu DS, Kadell BM, et al. Accuracy of nonfocused helical CT for the diagnosis of acute appendicitis: a 5-year review. AJR 2002;178(6): 1319-25.

[7] Peck J, Peck A, Peck C, et al. The clinical role of noncontrast helical computed tomography in the diagnosis of acute appendicitis. Am J Surg 2000;180(2):133-6.

[8] Wijetunga R, Tan BS, Rouse JC, et al. Diagnostic accuracy of focused appendiceal CT in clinically equivocal cases of acute appendicitis. Radiology 2001;221(3):747-53.
[9] Stroman DL, Bayouth CV, Kuhn JA, et al. The role of computed tomography in the diagnosis of acute appendicitis. Am J Surg 1999;178(6):485-9.

[10] Balthazar EJ, Birnbaum BA, Yee J, et al. Acute appendicitis: CT and US correlation in 100 patients. Radiology 1994;190(1):31-5.

[11] Lowe LH, Penney MW, Stein SM, et al. Unenhanced limited CT of the abdomen in the diagnosis of appendicitis in children: comparison with sonography. AJR 2001;176(1):31-5. 